Torben Vestergaard*

\title{
Writing English Grammars for Danes: bridging the gap between prescriptivism and descriptivism
}

Linguistics, for the better part of this century, has had a propensity for thinking in terms of dichotomies; and whereas some of these, such as 'signifiant' - 'signifié' or 'paradigm' - 'syntagm', serve purely descriptive purposes, many others have come to acquire the status of shibboleths: surely, real linguists work with 'synchronie' rather than 'diachronie', with 'form' rather than 'substance', or with 'competence' rather than 'performance'. And yet, none of these dichotomies seem to have aroused so violent emotions as the distinction between 'descriptive' and 'prescriptive', with the battle against 'prescriptivism' on the part of real, 'scientific linguistics' arguably reaching its rhetorical culmination in Hall's (1950/1960) book, characteristically entitled Leave your Language Alone.

It can be argued, however, that in their wholesale rejection of normative attitudes to language, members of the linguistic profession have turned their backs to an important fact about language communities. For since people will mark their personal identities and define their group allegiances through any behavioural means available, and since all languages are used by differing groups of people (even the smallest and most homogeneous speech community will at the very least be differentiated into such groups as and older and younger speakers as well as males and females), it follows that all languages, even the smallest, will be heterogeneous and variable systems (see e.g. Labov, 1972). This places even the most descriptively orientated of scientific linguists in a dilemma, for with a huge and possible infinite number of variants to choose between, he cannot possibly describe everything, no matter how hard he tries, and, accordingly, he will have to choose one

* Torben Vestergaard

Aalborg Universitet

Institut for sprog og internationale kulturstudier

Havrevangen 1

DK-9000 Aalborg 
or a few variants as the basis for his description. But thereby, willynilly, he inevitably falls into the quagmire of prescriptivism, as, simply by virtue of having been selected as the basis for linguistic description, a given variant will be exalted to the status of norm. ${ }^{1}$

In this note I am going to argue that even though grammars in general, and grammars for foreign students in particular, are necessarily and quite legitimately bound to be normative, ${ }^{2}$ it is possible and in fact necessary to reconcile the normative and the descriptive approaches. By way of illustration, I will discuss two concrete examples, both from the syntax of the English modal verbs.

\section{Choosing a norm}

As it is one of the tenets of structural linguistics that no language, and no variant of any one language, is better than others (e.g. Trudgill, 1975), it might appear that the question of which variant to aim at would be a non-issue for the foreign student. However, it is probably true of all language communities that there is a variant which members regard as the most neutral and the most suitable for purposes of wider, public communication. This variant is known as the standard variant, and this is also the variant that native speakers find the most suitable for foreigners, whether they themselves use it or not.

A Danish example will illustrate this: an English speaking colleague of mine, herself a sociolinguist, who lives and works in Denmark was once corrected by a group of Danes for using the local pronunciation, [o:ns '], of the name of her city of residence, Odense (standard pronunciation: [o? $\left.\mathrm{D}^{\prime} \mathrm{ns} \mathrm{s}^{\prime}\right]$ ). When she objected that this was how everyone else pronounced it, the answer was, 'Oh, but that's different: you're a foreigner.'

On top of native speakers' preference for foreigners using the standard variant, it is worth noting that all other variants than the standard will carry connotations about group membership that in the

\footnotetext{
1 Thus, for instance, the Collins/Cobuild Grammar, this the most descriptive of descriptive enterprises, is being advertised as 'the new authority on the English language'.

2 I regard 'normative' and 'prescriptive' as having the same denotative content, and I shall use them interchangeably, although the latter is certainly burdened with the more negative connotations.
} 
overwhelming majority of cases will be false, almost by definition, as long as we are talking about foreigners. And finally: for the foreigner embarking on an academic study of the language, the choice is even easier, as the standard variant will be the form of the language which is most commonly employed in all those professional contexts for which students are in the process of acquiring linguistic and cultural competence. ${ }^{3}$

It may be in order at this point to note that the standard variant of a language is not necessarily the most formal variant. A standard language can be used across the ranges of situations and subjects, from rituals and ceremonies, sacred and profane, over public debates on complex political or academic subjects, to private talks about the most trivial everyday matters, and it can abound with swearwords and other taboo words. In this respect the standard differs from non-standard variants, since it alone will have been developed for use in the most formal functions. Moreover, there will be speakers who use the standard in more formal situations only, but employ a non-standard variant for everyday purposes, which, of course, is the reason why 'standard' is often confused with 'formal'.

If we now turn our attention to English and restrict ourselves to the morphological and syntactic levels, it appears that standard English is spoken and written throughout the English speaking world, i.e. Great Britain, Ireland, North America, southern Africa, Australia and New Zealand, with geographical variations which, from the foreign student's point of view, are negligible, although it may be that there are greater morphological differences, particularly in verb inflection, between American and English English than commonly assumed, cf. Preisler, 1995. (There are, of course obvious lexical differences reflecting, partly, the differing geological, climatic, etc. surroundings, partly the dif-

3 When I am talking about the standard variant, I am referring to a phenomenon existing on the lexical, syntactic, morphological and phonological levels. On the phonetic level, like all other variants it can be pronounced with various different accents, and as far as standard English English is concerned, the accent characteristic of the top of the social scale, variously known as 'RP', 'BBC English', 'public school English', etc., is hardly the most suitable for foreigners as it carries associations about group membership which in most cases would be as false as those carried by nonstandard dialects. 
fering sociopolitical histories of the various English speaking countries). ${ }^{4}$

But even if 'Standard English' is a relatively unambiguous phenomenon, there is still a series of choices facing grammar writers, unless, totally unrealistically, they aim at covering everything falling within the coverage of the term. We have to realize that just as any 'language' is infinitely variable, so any variant of a language, including the standard, is subject to variation and change; and in the special case of grammars for foreign students the problem es even more pronounced: as no speaker, let alone a foreign student, will ever come to master the whole gamut of varieties contained within the variant of the language he aims at, the grammar writer will have to decide what to include and what to leave out. One possibility, and the only one that can be practised with a hundred per cent consistency, is for the grammarian to restrict himself to describing only those constructions which he will recommend that his readers should adopt. Once that principle has been abandoned, as it will have to be in any reasonably comprehensive grammar for university students, it is hard to make principled decisions in each individual instance. In my own case, for instance (Vestergaard 1985/1993), I state ( 8 8.3, note 2 ) that in modern English, unlike Danish, personal pronouns cannot be postmodified by restrictive relative clauses, knowing full well that in a variant of English that educated speakers can be assumed to be familiar with, viz. the English of Shakespeare's plays and the King James Bible, the construction is perfectly natural. And again, although I mention the phenomenon of 'preposition stranding' (but not the term) in my discussion of relative pronouns governed by prepositions, and although I point out that the construction is often avoided in formal writing (e.g. $§ 8.47$ ), I do not mention the fact that, regardless of the level of formality, the tendency to avoid the construction is far more pronounced in English than in Danish, where there is hardly any normative pressure against it. Conversely, I do mention that 'left dislocation', although it exists in English, is considerably less frequent than in Danish ( $§ 10.10$, note).

4 The phonological system, of course, differentiates Englsih into two major dialects: rhotic and non-rhotic, and within the former there is a further bifurdcation into dialects with and without phonological distinctions between long and short vowels. 


\section{Compromising between prescriptivism and descriptivism}

\section{1. 'shall' and 'will' with future reference}

There are four basic ways of referring to the future in English: the simple present tense, the present progressive, be going to plus infinitive, and modal plus infinitive. The modal employed here is will in all varieties of English except formal English English, which differs from all other varieties in using shall plus infinitive in the first person and will in all other persons (Quirk et al. 1972:87):

I shall/will talk to them next week.

you/he/etc. will talk to them next week.

As Quirk et al. state, prescriptive usage has 'exerted considerable influence' in the direction of shall in English English. Bloomfield characterizes the rule prescribing shall as a 'speculative notion' and 'fanciful dogma' invented by authorities and authoritarians (1933:7, 500), and according to Hall (1960:24) the rule was simply made up by a seventeenth century grammarian, 'one John Wallis'. That the distinction between shall and will does not seem to come naturally, even to natives, is further evidenced by the amount of space dedicated to it by guides to 'good usage': Partridge (1963) spends the better part of four columns on the phenomenon, Wood (1982) almost three pages; and Swan (1995), although noting that the use of shall is on the decrease, does accord about two pages to the problem.

Since, in the first place, will, in all persons, is thus acceptable throughout the English speaking world, and, secondly, the rule prescribing shall in the first person is of doubtful linguistic legitimacy, there would on the face of it seem to be a strong case for grammarians simply to make the statement that in those cases where the modal-plusinfinitive option is chosen, the modal used is will. The information that in one variant of English there is prescriptivist pressure for using shall in the first person could then be relegated to a footnote. However, as there are still native speakers of English whose notions of propriety, regardless of how they were acquired, are offended by the 'incorrect' use of the two modals (cf. the works by Partridge and Wood referred to above), and as university students of English are preparing for a career as professional speakers and writers of English, it might be argued that 


\section{8}

they should at least be able to put on a linguistic behaviour conforming with the strictest etiquette, even if that etiquette is not in accordance with descriptive fact, and the grammarian would therefore be doing his readers a disservice unless he overcame his own descriptive qualms and recorded the prescriptive rules, in spite of the fact that these rules dictate a usage deviating from the one normally encountered and generally accepted.

\section{2. possibility, permission, necessity, and obligation}

If,for the sake of the argument, we ignore the distinctions between epistemic, deontic and dynamic modality, the traditional statement concerning the use of can, may, have to, and must expressing possibility, permission, necessity and obligation amounts to something like the following:

\section{Possibility}

Can denotes an 'actual possibility' whereas may denotes an 'uncertain possibility':

Stockholm can be cold in winter.

I may not be back until after midnight.

\section{Permission}

Permission is expressed by may and, colloquially, can:

May I make a suggestion?

Can I take the car tonight?

\section{Necessity}

Necessity can (a) be imposed by somebody else (compulsion), it can (b) arise out of logic, it can (c) be the result of an inner urge, or it can (d) derive from outer circumstances. In all cases except (d), it is expressed by must:

You must do as you are told.

He must be at least 70 .

I must say I'm impressed.

I have to meet them at eight.

Out of this somewhat confusing picture there arose, at least in English English, a nice symmetrical system where the choice between on the 
one hand can and have to, and on the other may and must was consistently determined by the source of the modality, thus:

$\begin{array}{lll} & \text { external } & \text { internal } \\ \text { possibility } & \text { can } & \text { may } \\ \text { permission } & \text { can } & \text { may } \\ \text { necessity } & \text { have to } & \text { must } \\ \text { obligation } & \text { have to } & \text { must }\end{array}$

This system, then, would explain the distinctions between

1.a. The door can be locked. (the possibility exists)

b. The door may be locked. (it may or may not be, I don't know)

2.a. Can we smoke in here? (is it permitted?)

b. May I make a suggestion? (do you permit?)

3.a. There has to be a way out. (necessarily, otherwise, how did we get in?)

b. You must be joking. (I'm sure)

4.a. I have to meet them at eight.

b. I must say I'm impressed.

A beautiful situation of the type that structural linguists are always on the lookout for, as it permits us to demonstrate to our students that 'grammar' is not just a collection of disconnected rules that have to be learned by heart, but a coherent and logical system in which, once you have understood its inherent logic, rote learning becomes unnecessary.

However, no sooner had the new system established itself than it began to disintegrate, and the following counter-examples to 2.b., 3.b., and 4.b, are now perfectly possible:

Can I make a suggestion?

You've got to be joking.

Do you have to be playing that revolting music all the time?

Such cases instantiate the point made in the introduction to this note: that all languages are inherently variable and heterogeneous systems at the same time comprising vestiges of former patterns and the beginnings of new ones. So, in addition to displaying neat and orderly grammatical structures, the grammar will also have to show how linguistic systems are systems in constant development. Moreover, 
wherever there is variation, there is scope for prejudice, and if that prejudice is wide-spread enough to be recorded in the more important 'good usage guides', it will be the grammarian's duty to at least make a note of the fact in spite of his or her possible descriptivist leanings.

\section{Conclusion}

As will have appeared, I envisage a dual role for a university grammar for foreign students: The grammar should of course assist students in their acquisition of the foreign language by bringing new structures and constructions to the students' awareness, but along with that, the grammar course should also teach them about language, in that it should make them aware that the language is not just a practical skill nor a series of disconnected rules, but a coherent, self-contained, system.

Moreover, many of the students will be in the situation where the variant which they need to learn to command, at least in writing, will be quite different from the one they employ in spontaneous and informal conversation. The grammar course could here be the place where they discover that in addition to being a coherent system, language is also a variable system always fuzzy at the edges: it will always encompass traces of earlier systems as well as the beginnings of future systems, and although all varieties cannot possibly be part of the foreign students' own spontaneous and unreflected use of the language, there may well be contexts where normative attitudes in the foreign language community will expect them to know and be able to use variants different from the one they use for the purposes of everyday communication.

\section{References}

Bloomfield, L. (1933): Language. London: Allen and Unwin.

Hall, R.A. (1960): Linguistics and your Language (1950. Leave your Language Alone) New York: Anchor Books.

Labov, W. (1972): Sociolinguistic Patterns. Philadelphia: University of Pennsylvania Press.

Palmer, F. (1987): The english Verb. London: Longman.

Partridge, E.(1963): Usage and Abusage. Harmondsworth: Penguin Books.

Preisler, B. (1995) Standard English in the World. Multilingua 14. 341-362. 
Quirk, R. et al. (1972): A Grammar of Contemporary English. London: Longman.

Swan, M. (1995): Practical englsih Usage. Oxford: Oxford University Press.

Trudgill, P. (1975): Accent, Dialect and the School. London: Edward Arnold.

Vestergaard, T. (1985/1993): Engelsk Grammatik. Copenhagen: Schønberg.

Wood, F. T. (1982): Current English Usage. (revised by R.H. Flavell \& L.M. Flavell) London: MacMillan. 
122 